\title{
Point-of-care ultrasound curriculum for internal medicine residents: what do you desire? A national survey
}

\author{
Tycho J. Olgers ${ }^{*}$ (i) and Jan C. ter Maaten
}

\begin{abstract}
Background: Point-of-care Ultrasound is a relative new diagnostic tool for internists. Since 2019, it is a mandatory skill for internal medicine residents in the Netherlands but an ultrasound curriculum still has to be developed. In this study we explored the current ultrasound training program and educational wishes from internal medicine residents.

Methods: We have undertaken a national study in March 2019 using an online questionnaire. All internal medicine residents in the Netherlands were invited to respond.

Results: A total of 247 from 959 (26\%) residents completed the questionnaire. The majority of residents (78.6\%) received less than $10 \mathrm{~h}$ of ultrasound training and $40 \%$ has never made an ultrasound at all. Almost all residents (92\%) indicate that ultrasound is a useful skill for the internist. They report that the most useful applications are ultrasound of the inferior vena cava, kidneys, abdominal free fluid, deep vein thrombosis, heart and lungs. The main perceived barrier to perform ultrasound is the lack of availability of experts for bedside supervision.

Conclusion: This study confirms the need for a national ultrasound curriculum for internal medicine residents and may contribute to the development of an ultrasound curriculum in line with residents educational needs. We should begin the curriculum with the previously mentioned applications, perceived by internal residents as most useful. Additional applications can be appended in the future. Finally it is necessary to expand the number of experts to supervise the residents.
\end{abstract}

Keywords: Ultrasound, Ultrasound curriculum, Internal medicine, POCUS

\section{Background}

PoCUS (Point-of-care ultrasound) is an emerging and relatively new skill for internists but little is known about the optimal content and duration of the training program to become competent [1]. In The Netherlands, the internal medicine (IM) residency training program has been updated in 2019 and this states that PoCUS is as a mandatory skill but the content of the educational program for PoCUS has yet to be developed [2]. Recently, a uniform ultrasound curriculum for internal medicine was proposed containing a blueprint for such a curriculum, in line with existing European ultrasound curricula [3-5].

\footnotetext{
* Correspondence: t.j.olgers@umcg.nl

Department of Internal Medicine, Univ Groningen, University Medical Center Groningen, Huispostcode AA41, Postbus 30.0016, 9700, RB, Groningen, the Netherlands
}

This blueprint can be a starting point for a more detailed elaboration about choosing the core applications for every internist is an important issue.

It is questionable if all residents should become competent in every ultrasound application. Internal medicine is a large specialty with many subspecialties and not all applications may be useful for every subspecialty. In this way, internal medicine differs from other specialties like cardiology or intensive care medicine. Secondly, if residents are able to become competent, it is unsure if they can stay competent in each application due to limited exposure time and training opportunities within their subspecialty. These are important considerations that curriculum developers should take into account.

It is unknown if the proposed core application meet the needs of the residents. Residents are faced with 
increasing competency-based programs, individualized training programs and they are becoming more selfregulated learners [6]. Accounting for their wishes and needs may increase intrinsic motivation and learning process efficacy. Some studies have already investigated internal medicine resident wishes for ultrasound, but these results may not be applicable in the Netherlands and Europe due to differences in healthcare systems and local needs $[7,8]$.

We have undertaken a national survey to establish the needs and wishes of internal medicine residents for our national PoCUS educational program. These results can be used for further curriculum development in the Netherlands but may also apply for other European countries who are initiating ultrasound programs for IM.

\section{Methods}

We have undertaken a cross-sectional national survey study in the Netherlands. We have invited all internal medicine residents to complete this questionnaire. The content of this questionnaire was developed by two researchers who are also national ultrasound experts in PoCUS for internal medicine. The final draft of this questionnaire was presented to the Dutch national taskforce for internal medicine ultrasound. The survey was finalized after incorporating their suggestions. The survey was distributed in March 2019 using an online survey tool (www.thesistoolspro.com). All residents for internal medicine are registered by the Dutch Internal Medicine federation (NIV). An invitation for this survey was distributed by the secretary board of the NIV. After 2 months all residents received a reminder to complete this survey. The questionnaire included demographic data, questions about current PoCUS training and practice, and questions about the perceived usefulness and wishes for PoCUS. The exact content of the survey can be found as a Additional file 1. Ethical approval was waived by our local medical ethics committee.

The Dutch residency program for internists consist of 4 years general internal medicine with several rotations. After 4 years they start their fellowship within a subspecialty or extended rotations for a multiple profile. Residents for other specialties (for example cardiology, respiratory medicine, gastro-enterology) follow 2 years of common trunk general internal medicine. Results are displayed as frequencies.

\section{Results}

A total of 247 of 959 residents completed this survey yielding a response rate of $26 \%$. The demographics of the respondents are shown in Table 1.

This shows a heterogeneous distribution of subspecialty and year of residency.
Table 1 Demographics of residents

\begin{tabular}{|c|c|}
\hline Demographics & N $247(\%)$ \\
\hline \multicolumn{2}{|l|}{ Age (years) } \\
\hline $26-30$ & $93(37.7)$ \\
\hline $31-35$ & $130(52.6)$ \\
\hline $36-40$ & $23(9.3)$ \\
\hline $41-45$ & $1(0.4)$ \\
\hline \multicolumn{2}{|l|}{ Sexe } \\
\hline Male & $83(33.6)$ \\
\hline Female & $164(66.4)$ \\
\hline \multicolumn{2}{|l|}{ Residency (year) } \\
\hline 1 & $33(13.4)$ \\
\hline 2 & $48(19.4)$ \\
\hline 3 & $43(17.4)$ \\
\hline 4 & $48(19.4)$ \\
\hline 5 & $41(16.6)$ \\
\hline 6 & $33(13.4)$ \\
\hline Other & $1(0.4)$ \\
\hline \multicolumn{2}{|l|}{ Subspecialty } \\
\hline General & $41(16.6)$ \\
\hline Vascular & $6(2.4)$ \\
\hline Geriatrics & $19(7.7)$ \\
\hline Endocrinology & $15(6.1)$ \\
\hline Nephrology & $13(5.3)$ \\
\hline Hematology & 9 (3.6) \\
\hline Oncology & $22(8.9)$ \\
\hline Acute medicine & $14(5.7)$ \\
\hline Infectious disease & $11(4.5)$ \\
\hline Intensive care & $14(5.7)$ \\
\hline Common trunk internal medicine & $76(30.8)$ \\
\hline Common trunk other & $4(1.6)$ \\
\hline Other & $3(1.2)$ \\
\hline \multicolumn{2}{|l|}{ Current type of hospital } \\
\hline Academic & $129(52.2)$ \\
\hline Non-academic top clinical teaching hospital & $92(37.2)$ \\
\hline Non-academic normal teaching hospital & $26(10.5)$ \\
\hline \multicolumn{2}{|l|}{ Ultrasound machine available } \\
\hline Yes, handheld & 9 (3.6) \\
\hline Yes, mobile & $136(55.1)$ \\
\hline Yes, both & $7(2.8)$ \\
\hline None & $93(37.7)$ \\
\hline Missing & $2(0.8)$ \\
\hline \multicolumn{2}{|l|}{ PoCUS educational sessions } \\
\hline Yes & $92(37.2)$ \\
\hline No & 155 (62.8) \\
\hline
\end{tabular}


The first part of the questionnaire concerned questions about current use of and education in PoCUS. The IM residents report that PoCUS is used by internists in the minority of hospitals (32.8\%) in contrast to their reported use of PoCUS by emergency physicians (66.8\%). They state that PoCUS educational sessions are only available in the minority of hospitals (37.2\%). More than half $(55.9 \%)$ of residents did not have any previous ultrasound training (Table 2) and another $22.7 \%$ had less than $10 \mathrm{~h}$ of ultrasound training.

A significant part of residents (40\%) has never made any ultrasound study at all. If residents have performed ultrasounds themselves, the most common application was the inferior vena cava (IVC) $(N=90(36.4 \%))$. Some residents feel competent for themselves for a few applications but most residents feel completely unqualified (Fig. 1).

The second part of the questionnaire investigated the perceived usefulness and future expectations. Respondents indicated that the most useful diagnostic core applications are IVC, renal and abdominal free fluid, followed by deep vein thrombosis, heart and lungs (Table 3). Aorta and gallbladder are considered least useful. Strikingly, 20 residents $(8.1 \%)$ think that not a single indication is useful for every internist, the reason for this was not registered. Finally, other useful indications mentioned were thyroid ultrasound and determining hepatosplenomegaly.

The main perceived barriers are insufficient experts available for supervision, insufficient knowledge and skills about PoCUS and lack of time for practicing ultrasound. Other barriers were expecting limited exposure time to PoCUS and therefore doubting the usefulness of PoCUS for themselves. Finally, issues with financing ultrasound courses was mentioned several times.

\section{Discussion}

Our study shows that PoCUS education and experience is very limited for IM medicine residents in the Netherlands but very desired. Residents are almost

Table 2 Ultrasound training hours received during current residency

\begin{tabular}{ll}
\hline Course hours followed & $\mathrm{N}(\%)$ \\
\hline 0 & $138(55.9)$ \\
$1-10$ & $56(22.7)$ \\
$11-20$ & $28(11.3)$ \\
$21-30$ & $11(4.5)$ \\
$31-40$ & $4(1.6)$ \\
$41-50$ & $5(2.0)$ \\
$>50$ & $5(2.0)$ \\
\hline
\end{tabular}

unanimous that PoCUS will provide better and faster patient care and most of them believe they will use PoCUS within 5 years. Residents seem to have clear ideas what they think is important for their education in PoCUS and this is in line with previous studies [7, 8]. Curriculum developers should allow for their wishes to optimize the PoCUS educational program.

Although many ultrasound curricula already exist, some of which are very extensive, it is questionable if every country can fully adopt these curricula due to local and national differences in healthcare structure $[9,10]$. Also, there is no consensus at this moment on the content of ultrasound curricula specifically for internal medicine $[11,12]$. It is necessary to make choices in core applications because IM is a large specialty with many subspecialties. To become, and stay competent in PoCUS, enough training hours and patient encounters are mandatory but this may not be achievable for every IM resident. At this moment, it is not known how many training hours or performed exams are needed to become competent for each application. Some studies show that limited exposure time is sufficient to master IVC ultrasound [13]. The American college of radiology demands for nonradiology physicians performing ultrasound to follow at least $200 \mathrm{~h}$ category 1 continuous medical education in the subspecialty where ultrasound reading occurs, and supervision and/or performance, interpretation, and reporting of 500 cases relative to each subspecialty area interpreted (e.g., pelvic, obstetrical, thyroid, vascular) during the past 36 months in a supervised situation [14]. For IM residents the optimal training hours and number of exams performed to become competent has to become clear but using the entrustable professional activities (EPA) system might assist [3]. This system defines competence and need for supervision on five different levels and is based on the observed ultrasound performance instead of a fixed number of ultrasound studies.

We have to design ultrasound curricula with a basic set of core applications useful for every IM resident, that can be extended with more specialized application depending on residency year and subspecialty, and are in line with local and national healthcare wishes and regulations. Ultrasound introductory courses should focus on these core applications and limit the total number of applications.

We have shown that residents have clear ideas how educators should construct the ultrasound curriculum specifically the most useful core applications for IM. According to IM residents in the Netherlands, IVC, renal and abdominal free fluid, should be the core diagnostic ultrasound applications, supplemented by deep vein thrombosis, heart and lung ultrasound. Ultrasound curricula can be designed in a way that all residents become 


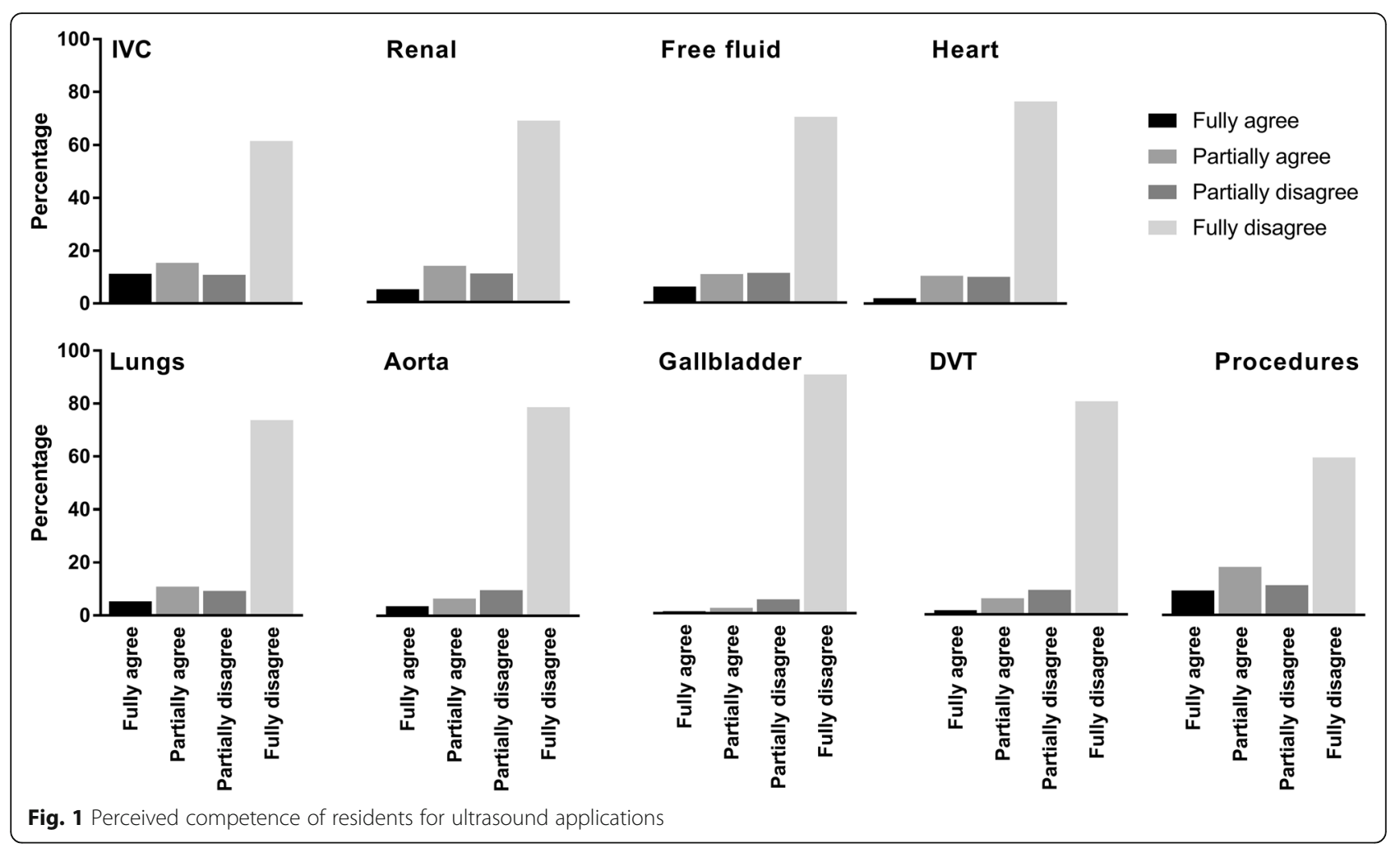

competent for these applications. Additional applications can be learned at later stages of their residency program and will be determined by residents own wishes, subspecialty and regional healthcare structure.

Finally we have to increase the number of ultrasound experts who can supervise the residents. At this moment there is insufficient time to practice, especially practice time together with an expert.

Table 3 Most useful Core applications indicated by respondents

\begin{tabular}{lll}
\hline Core application & Yes N (\%) & No N (\%) \\
\hline IVC & $197(79.8)$ & $50(20,2)$ \\
Renal & $188(76,1)$ & $59(23,9)$ \\
Abdominal Free Fluid & $156(63,2)$ & $91(36,8)$ \\
Procedures & $148(59,9)$ & $99(40,1)$ \\
Lungs & $122(49,4)$ & $125(50,6)$ \\
DVT & $97(39,3)$ & $150(60,7)$ \\
Heart & $79(32)$ & $168(68)$ \\
Aorta & $42(17)$ & $205(83)$ \\
Gallbladder & $30(12,1)$ & $217(87,9)$ \\
None & $20(8,1)$ & $227(91,9)$ \\
Other & $4(1,6)$ & $243(98,4)$ \\
\hline
\end{tabular}

Most residents (77.3\%) are convinced they will use PoCUS within their own working environment

The final question was about perceived barriers. The overwhelming majority (96.8\%) experiences at least one limitation for performing PoCUS (Table 4)

\section{Limitations}

Our study may be limited by a response rate of $26 \%$, although this is a reasonable response rate for survey studies (mean web-based data collection response rate 27.6\%) [15]. Nonetheless, it is possible that a selection bias exist with responders being more enthusiastic about ultrasound with different ideas than non-responders. We did not contact a subgroup of non-responders. Also, we did not test our survey in a small group in advance so misinterpretation of questions cannot be excluded.

Table 4 Perceived barriers for PoCUS use

\begin{tabular}{ll}
\hline Limitations for ultrasound & $\mathrm{N}(\%)$ \\
\hline Insufficient experts available & $150(60,7)$ \\
Insufficient supervised practice time & $142(57,5)$ \\
Insufficient knowledge of PoCUS & $140(56,7)$ \\
Insufficient practice time & $126(51)$ \\
Insufficient training available & $103(41,7)$ \\
No ultrasound machine & $82(33,2)$ \\
No national guideline from NIV & $53(21,5)$ \\
Resistence from other specialties & $51(20,6)$ \\
Other & $27(10,9)$ \\
No limitations & $8(3,2)$ \\
\hline
\end{tabular}

${ }^{a}$ NIV Nederlandse Internisten Vereniging (Dutch Internal Medicine Federation), PoCUS Point-of-care ultrasound 
Finally, we did not have open questions, so other important issues regarding ultrasound education may be missed.

\section{Conclusion}

We have shown that IVC, renal, abdominal free fluid, deep vein thrombosis, cardiac and lung ultrasound are perceived as most useful core applications for IM residents by IM residents. Ultrasound curricula need to take these wishes into account. These applications should be the basic core applications for ultrasound courses and the national ultrasound curriculum. They can be extended by several other more specialized applications depending on year of residency, subspecialty and regional healthcare structure with additional training and courses.

\section{Supplementary information}

Supplementary information accompanies this paper at https://doi.org/10. 1186/s12909-020-1949-4.

Additional file 1. Survey POCUS Internal medicine.

\section{Abbreviations}

EPA: Entrustable professional activities; IM: Internal medicine; IVC: Inferior vena cava; PoCUS: Point-of-care ultrasound

\section{Acknowledgements}

We would like to thank the members of the Dutch internal medicine ultrasound taskforce for their contribution to the development of the questionnaire.

\section{Authors' contributions}

$\mathrm{TO}$ and JtM conceived the study idea and contributed to the analysis and interpretation of the data. TO collected the data and drafted the first manuscript, all authors helped revise it critically. All authors gave final approval of the submitted paper.

\section{Funding}

None.

\section{Availability of data and materials}

Supporting data can be requested from the corresponding author by email (t.j.olgers@umcg.nl).

\section{Ethics approval and consent to participate}

Ethical approval was waived by our medical ethics committee (METC UMC Groningen). We have followed our institutional research guideline (UMCG kaderreglement nWMO, versie 2.0, mei 2017) for educational research. Participants provided written consent.

\section{Consent for publication}

Not applicable.

\section{Competing interests}

The authors declare that they have no competing interests.

Received: 15 November 2019 Accepted: 27 January 2020 Published online: 31 January 2020

\section{References}

1. Arienti V. Camaggi V. Clinical applications of bedside ultrasonography in internal and emergency medicine. Intern Emerg Med. 2011;6(3):195-201.
2. Dutch internal medicine federation (NIV). National educational framework internal medicine. 2019. Available from: https://internisten.nl/sites/ internisten.nl/files/Landelijk\%20opleidingsplan\%20|G\%202019\%20Deel\%2 01\%20\%28def_v09\%29_1.pdf. Accessed Feb 2019.

3. Olgers TJ, Azizi N, Blans MJ, Bosch FH, Gans ROB, Ter Maaten JC. Point-ofcare ultrasound (PoCUS) for the internist in acute medicine: a uniform curriculum. Neth J Med. 2019;77(5):168-76.

4. Arienti V, Di Giulio R, Cogliati C, Accogli E, Aluigi L, Corazza GR, Ultrasound SIMI Study Group. Bedside ultrasonography (US), Echoscopy and US point of care as a new kind of stethoscope for internal medicine departments: the training program of the Italian internal medicine society (SIMI). Intern Emerg Med. 2014;9(7):805-14.

5. The society for acute medicine (SAM). Focused Acute Medicine. Ultrasound (FAMUS) curriculum pack. 2018. Available from: https://www.acutemedicine. org.uk/what-we-do/training-and-education/famus/. Accessed 29 Jan 2020.

6. van Houten-Schat MA, Berkhout JJ, van Dijk N, Endedijk MD, Jaarsma ADC, Diemers AD. Self-regulated learning in the clinical context: a systematic review. Med Educ. 2018;52(10):1008-15.

7. Kessler C, Bhandarkar S. Ultrasound training for medical students and internal medicine residents--a needs assessment. J Clin Ultrasound. 2010; 38(8):401-8

8. Schnobrich DJ, Gladding S, Olson AP, Duran-Nelson A. Point-of-care ultrasound in internal medicine: a National Survey of educational leadership. J Grad Med Educ. 2013;5(3):498-502.

9. International federation for emergency medicine (IFEM). Point-of care ultrasound curriculum guidance. 2014. Available from: https://www.ifem.cc/ curricula-for-emergency-medicine/. Accessed 29 Jan 2020.

10. American College of Emergency Physicians. Emergency Ultrasound Imaging Criteria Compendium (policy statement). 2014. Available from: https://www. acep.org/globalassets/sites/acep/media/ultrasound/ usimagingcriteriacompendium.pdf. Accessed Apr 2019

11. LoPresti CM, Schnobrich DJ, Dversdal RK, Schembri F. A road map for pointof-care ultrasound training in internal medicine residency. Ultrasound J. 2019;11(1):10.

12. LoPresti CM, Jensen TP, Dversdal RK, Astiz DJ. Point-of-care ultrasound for internal medicine residency training: a position statement from the Alliance of academic internal medicine. Am J Med. 2019;132(11):1356-60.

13. Brennan JM, Blair JE, Goonewardena S, Ronan A, Shah D, Vasaiwala S, Brooks E, Levy A, Kirkpatrick JN, Spencer KT. A comparison by medicine residents of physical examination versus hand-carried ultrasound for estimation of right atrial pressure. Am J Cardiol. 2007;99(11):1614-6 Epub 2007 Apr 18.

14. $A C R$ - SPR -SRU practice parameter for the performing and interpreting diagnostic ultrasound examinations. Revised 2017. https://www.acr.org/-/ media/ACR/Files/Practice-Parameters/us-perf-interpret.pdf?la=en

15. Blumenberg C, Barros AJD. Response rate differences between web and alternative data collection methods for public health research: a systematic review of the literature. Int J Public Health. 2018;63(6):765-73.

\section{Publisher's Note}

Springer Nature remains neutral with regard to jurisdictional claims in published maps and institutional affiliations.
Ready to submit your research? Choose BMC and benefit from:
- fast, convenient online submission
- thorough peer review by experienced researchers in your field
- rapid publication on acceptance
- support for research data, including large and complex data types
- gold Open Access which fosters wider collaboration and increased citations
- maximum visibility for your research: over $100 \mathrm{M}$ website views per year
At BMC, research is always in progress.
Learn more biomedcentral.com/submissions 